\title{
ESTRATÉGIAS DO MELHORAMENTO GENÉTICO DA MANGA A VISANDO ATENDER A DINÂMICA DE MERCADO ${ }^{1}$
}

\author{
ALBERTO CARLOS DE QUEIROZ PINTO², FRANCISCO PINHEIRO NETO 3 , \\ TADEU GRACIOLLI GUIMARÃES ${ }^{4}$
}

RESUMO - O Brasil é um dos seis maiores produtores de manga do mundo com 1,3 milhão de toneladas e uma área de 75,2 mil hectares. No entanto, a exportação de manga, em 2010, foi de cerca de 140 mil toneladas, o que representou apenas $10,3 \%$ dessa produção. A diversificação na oferta da manga para os mercados interno e externo tem sido feita desde o fruto fresco de produção convencional, à manga orgânica de manejo bastante específico e, mais recentemente, há uma tendência no aumento da demanda pela manga processada. Para atender a essa demanda, deve-se não somente melhorar o parque industrial, mas também o desenvolvimento genético, as estratégias e a seleção de cultivares e técnicas de manejo que atendam às diversas exigências do mercado para frutos frescos, orgânicos e processados. Este trabalho tem como objetivo sugerir aos melhoristas de manga, estratégias eficientes na obtenção e seleção da chamada "cultivar ideal", e aos produtores e exportadores discutir técnicas mais eficientes que atendam às exigências de maior produção e qualidade da manga como resposta à dinâmica de demanda dos mercados internos e externos.

Termos para indexação - seleção de cultivar, estratégias de avaliação, qualidade da manga, técnicas de melhoramento e manejo.

\section{MANGO BREEDING STRATEGIES ON FOCUS TO THE DYNAMIC OF THE MARKET}

\begin{abstract}
Brazil is one of the largest mango producers in the world with 1,3 millions of tones from an area of 72,5 hectares. Nevertheless, the mango exports in 2010 was about 140 thousand tones which is approximately $10 \%$ of the total production. The diversification of mango supply to the internal and external markets has been done since the fresh mango from conventional production to the organic fruit from a specific management and also, most recently, there is a tendency for an increase demand of processed mango. To comply with these demands there is not only a need for the development of the processing industry, but also the improvement of mango cultivars and management techniques to attend the several exigencies of the market for conventional fresh, organic and processed fruits. This paper has the objective to suggest to the mango breeders efficient strategies to get and select the so called "ideal mango cultivar" as well as to discuss more efficient management techniques to attend the high production and quality of mango as an answer to the dynamic of the internal and external market demands.
\end{abstract}

Index terms - cultivar selection, evaluation strategies, mango quality, management and breeding techniques.

\section{INTRODUÇÃO}

O Brasil é um dos três maiores produtores de frutas do mundo com cerca de 43 milhões de toneladas em uma área de 2,5 milhões de hectares em 2009. As exportações saltaram de 296 mil toneladas em 1998 para 759 mil toneladas em 2010. A exportação de frutas frescas representou um montante superior a 900 milhões de dólares, enquanto as processadas representaram cerca de 2 bilhões de dólares no agronegócio de frutas (IBRAF, 2011).
A manga é a sexta mais importante fruta brasileira em área colhida com 75,2 mil hectares e a terceira em volume de exportação com 124,6 mil toneladas em 2010 (MAPA, 2011), representando um valor de exportação de cerca de 100 milhões de dólares (FOB). Porém, esse volume de exportação refere-se ao produto exportado na forma in natura, não havendo cifras relacionadas à manga processada. Considerando esse maior valor das exportações das frutas processadas brasileiras em relação às frutas frescas, é fácil concluir que as exportações de manga

\footnotetext{
${ }^{1}$ Palestra Sinfruit 095 - Simpósio Internacional de Fruticultura - Avanços na Fruticultura (17 a 21 Outubro)

${ }^{2}$ Eng. Agr. Dr. Professor visitante da Pós-graduação da UnB, consultor técnico em frutas tropicais, Brasília-DF. E-mail: alcapi@terra. com.br

${ }^{3}$ Eng. Agr. Dr. Pesquisador da Embrapa Semi-árido (CPATSA), Petrolina-DF. E-mail: pinheiro.neto@cpatsa.embrapa.br

${ }^{4}$ Eng. Agr. Dr. Pesquisador da Embrapa Cerrados (CPAC), Planaltina-DF. E-mail: graciolli@cpac.embrapa.br
} 
processada também seguem esse tipo de comportamento ascendente no mercado.

Como a produção até o presente momento tem sido basicamente para atender à demanda de frutas frescas, o melhoramento genético da manga, em diversas instituições nacionais e internacionais (PINTO, 1996; ROSSETTO et al., 1996; BRETTELL et al., 2004; HUMAN et al., 2009), quase sempre teve como objetivo a obtenção de cultivares de porte anão, resistentes a pragas e doenças, alta produtividade e excelente qualidade do fruto para o consumo in natura. No entanto, a dinâmica de mercado ao longo desses últimos 10 anos vem mudando, e a oferta da manga nos mercados consumidores é quase sempre influenciada por outros fatores, como o mercado étnico e a pressão de empresas produtoras, processadoras e exportadoras de manga. Portanto, não somente a manga para consumo a fresco, mas também a processada tornaram-se obrigatórias nos mercados interno e externo, obrigando a seleção de cultivares com dupla finalidade para atender a ambos os segmentos de produção.

Este trabalho tem como objetivo sugerir aos melhoristas de manga novas estratégias na seleção e obtenção da chamada "cultivar ideal", e aos produtores e exportadores, discutir técnicas mais eficientes que atendam às exigências de maior produção e qualidade da manga como resposta à dinâmica dos mercados interno e externo quanto ao consumo de manga in natura e processada.

\section{A DINÂMICA DE MERCADO E A QUALIDADE DA MANGA}

O mercado de manga no mundo mostra um consumo per cápita ainda baixo nos principais países importadores do Hemisfério Norte, principalmente se comparado com outras frutas, como maçã, pera e ameixa. Atualmente, o consumo de manga in natura está, em média, menor que $1 \mathrm{~kg} /$ pessoa/ano. Nos Estados Unidos, por exemplo, o consumo de manga é de 0,86 kg/pessoa/ano; nos países europeus, como França, Reino Unido, Alemanha e Bélgica, o consumo é de 0,29; 0,$37 ; 0,26$ e $0,21 \mathrm{~kg} /$ pessoa/ano, respectivamente. Somente a Holanda tem um consumo mais alto $(1,72$ $\mathrm{kg} / \mathrm{pessoa} / \mathrm{ano}$ ), o que demonstra a existência de muitos mercados que ainda devem crescer nesse aspecto. Entre os 10 maiores produtores de manga, o México (13,4 kg/pessoa/ano), a Tailândia $(21,89 \mathrm{~kg} /$ pessoa/ ano) e a Índia (11,29 kg/pessoa/ano) apresentam as mais altas taxas de consumo per cápita de manga no mundo, porém esses países consomem muito os produtos processados de manga. O Brasil e a China têm as menores taxas de consumo entre os grandes produtores de manga com 2,68 e 2,57 kg/pessoa/ano, respectivamente (GRANÇO et al., 2010).

A oferta de manga fresca (in natura) no mercado mundial vem expandindo-se ano após ano e deve-se principalmente à eliminação ou diminuição de tarifas e sanções aduaneiras e de barreiras fitossanitárias, devido ao uso da produção integrada, que limitava a exportação da manga brasileira. A União Europeia é o principal destino da exportação de manga brasileira devido à grande, rica e diversificada população daquele continente com mais de $300 \mathrm{mi}$ lhões de habitantes, cuja demanda por frutas frescas é elevada o ano todo. Granço et al. (2010), citando Comtrade (2007), relatam que entre 1991 e 2006 as exportações de manga brasileira para o mercado europeu cresceram em $1.450 \%$, passando de 16,7 mil para 242,8 mil toneladas. No entanto, o mercado internacional é cada vez mais exigente em relação à qualidade e à responsabilidade social e econômica na produção da manga.

Além da padronização no manejo, na logística de pós-colheita, incluindo as exigências ditadas pela cadeia de comercialização (embalagem, transporte, resfriamento e conservação), o produtor/exportador tem de se preocupar com a qualidade da manga ofertada quanto à aparência e ao sabor que se adaptem ao mercado importador (LIMA; MIRANDA, 2000).

O mercado internacional da manga é bastante influenciado pelo fator étnico na escolha da cultivar a ser consumida e pela própria decisão da empresa produtora, processadora e exportadora em explorar mais a variedade que atenda a uma determinada linha de produto de acordo com seu interesse, principalmente sucos. Essa decisão muda o mercado e a comercialização da manga no mundo de forma muito rápida e dinâmica. $\mathrm{O}$ crescimento da manga mexicana 'Ataulfo' no mercado norte-americano deve-se à enorme população de mexicanos naquele país, que tem preferencialmente escolhido essa cultivar no seu consumo diário. Esse fato levou, nos últimos 10 anos, à mudança de interesse de produtores mexicanos, brasileiros, equatorianos e peruanos pela produção da manga 'Ataulfo'. No entanto, essa variedade tem problemas de campo quanto à resposta à indução floral, baixo vingamento e produção irregular de frutos, além do baixo rendimento de polpa, levando a que muitas empresas já iniciem a recuperação de copa com outra variedade. A 'Carabao' tem sido solicitada a muitos produtores pela empresa de sucos Dole, o que incentiva a exploração de nova variedade e à mudança na demanda do mercado; grupos indianos têm difundido fortemente a 'Mallika' no mercado americano (Noris Ledesma, comunicação pessoal, junho 2011).

A grande aceitação das variedades de man- 
gas da Índia ('Dashehari', 'Alphonso', 'Mallika') e da Tailândia ('Kheo Savoy', 'Nam Doc Mai' e 'Okrong') na Inglaterra é também influenciada pela população de indianos e tailandeses naquele país, além da forte ligação histórica e diplomática entre os mesmos. Todas essas variedade são de coloração amarela, portanto diferente do padrão vermelho de coloração da casca internacionalmente aceito. O Brasil apresentou um aumento nas exportações entre 2009 e 2010 da ordem de $11 \%$, utilizando as variedades Tommy Atkins, Palmer, Kent e Keitt (MENTEN 2010). Porém, a grande concentração da produção e exportação brasileira de manga refere-se à 'Tommy Atkins' que, apesar de sua excelente coloração da casca e boa resposta à indução floral, apresenta baixa qualidade quanto ao sabor (Brix $<17 \%$ ) e à cor de polpa amarelo-esmaecida, além de problemas de suscetibilidade à malformação floral, à mosca-das-frutas, ao colapso interno de polpa e à alta exsudação de látex que afetam a quantidade e a qualidade do fruto no mercado consumidor.

Em mercado exigente em qualidade, a comercialização da manga fresca (in natura) parece ser bem mais complexa que seus produtos processados, em virtude de ser um produto altamente perecível. Nesse sentido, Lima e Miranda (2000) comentam que o processamento pode transformar a qualidade do produto por meio da homogeneização da matéria-prima, superando até suas possíveis deficiências. $\mathrm{O}$ ponto positivo nesse aspecto é que a dinamicidade do mercado de manga processada tem sido bem mais forte que a de frutos frescos, nesses últimos 10 anos. A tendência do mercado aponta para o aumento gradual na comercialização de alimentos prontos para consumo e de longa capacidade de conservação que, em resumo, referem-se aos processados. Não obstante, a quantidade de manga processada, ofertada no mercado internacional, ainda é insignificante e representa menos de $0,02 \%$ em relação à produção total de manga (SAÚCO, 2002). Porém, inúmeras empresas e indústrias processadoras de manga no Brasil e no mundo vêm tentando mudar esse panorama. A Indústria Del Valle-Mais, hoje pertencente à Coca Cola, possui área própria de exploração de cerca de 150 ha de manga 'Ubá' no município de Vazante-MG, além da compra de frutos de terceiros (inclusive da variedade Tommy Atkins) para produção de suco de manga. A Hacienda Camposol S.A. em Piura, Peru, usa cerca de $40 \%$ da sua produção de manga 'Kent' para elaboração de processado tipo polpa em fatias ou cubos congelados. Somente no ano de 2010, foram exportadas cerca de $72 \mathrm{mil}$ toneladas desse tipo de processado, principalmente para o mercado escandinavo. Portanto, seguindo essa nova tendência, a estratégia usada no melhoramento genético deveria também mudar o foco para criação de variedades de dupla finalidade para atender à dinâmica e às exigências do mercado atual.

\section{ESTRATÉGIAS PARA O MELHORAMENTO GENÉTICO}

O melhoramento genético da manga tem sido realizado por diversas instituições nacionais e internacionais quase sempre com o objetivo de atender às características requeridas por alguns ou todos os três principais segmentos da cadeia produtiva: produtores, distribuidores e consumidores (PINTO, 1996; ROSSETTO et al., 1996; BRETTELL et al., 2004; HUMAN et al., 2009). Os produtores anseiam por variedades que apresentem maior produtividade e estabilidade de produção e sejam de fácil manejo nos tratos culturais e adaptadas às condições climáticas adversas da região para onde foi desenvolvida. Os distribuidores desejam variedades que resistam ao manuseio e ao transporte e, finalmente, os consumidores procuram manga de melhor qualidade, primeiro atraídos pela cor do fruto e depois pelo sabor.

A influência do chamado mercado étnico e a importância de produtos processados de manga na mesa do consumidor têm mudado nos últimos 10 anos a característica da fruta demandada, o que deve afetar a estratégia a ser usada pelo melhorista na busca de características importantes para obtenção de nova cultivar. Assim sendo, novas variedades de manga somente serão bem aceitas se apresentarem, para os diversos segmentos da cadeia produtiva, duas ou mais vantagens em relação às mais comercializadas no mercado e com a possibilidade do uso de dupla finalidade, ou seja, uso no consumo in natura e como processado.

Em geral, as características selecionadas para a obtenção de uma "variedade ideal" nos programas de melhoramento genético incluem aquelas características relativas tanto à planta quanto ao fruto, como as que seguem:

Planta: Produtiva (média de $40 \mathrm{t} / \mathrm{ha}$ em densidade de 476 planta/ha), porte baixo e copa espraiada; de produção precoce e regular, resistente às principais pragas e doenças. Frutos: Peso de $400 \mathrm{a}$ $500 \mathrm{~g}$ e de forma ovalada (similar à 'Haden'); quando maduro (ponto de consumo) com coloração da casca vermelha a vermelho-arroxeada brilhante com laivos amarelos, polpa de cor laranja intenso, sem ou com pouca fibra, teor de açucares (Brix) acima de 18\% e ligeiramente ácida com outras boas qualidades organolépticas (odor, textura), livres de desordens fisiológicas, vida de prateleira ("shelf-life") entre 3 
e 4 semanas e resistência ao transporte (LAVI et al., 1996; TOMER et al., 1996; CILLIERS et al., 1996; IYER; DINESH, 1996; IYER; DEGANI, 1997; PINTO, 1996; PINTO; FERREIRA, 1999; SAÚCO, 1999). Com relação ao melhoramento genético, visando à seleção de porta-enxertos, as principais características requeridas são: poliembrionia; porte anão; tolerância às condições adversas do solo; resistência a doenças e boa compatibilidade com a variedade copa. Embora todas essas características sejam fundamentais para manter a competitividade e o sucesso comercial, combinar todas essas características em uma única cultivar é uma missão praticamente impossível para o melhorista. Para que as chances aumentem na difícil tarefa de desenvolver nova cultivar com a maioria das características desejáveis, é necessário que o melhorista tenha à sua disposição uma aceitável variabilidade genética, excelentes conhecimentos sobre a biologia floral, sobre o modo de reprodução e a herdabilidade dos caracteres desejados.

A decisão estratégica do melhorista quanto ao trabalho a longo ou médio prazo depende do estágio em que se encontra o seu conhecimento sobre manga e a disponibilidade de recursos financeiros, materiais e humanos. Além disso, a introdução de germoplasma tanto de espécies do gênero Mangífera quanto de variedades dentro da espécie Mangifera indica com características importantes e inovadoras são de grande valia para o melhoramento da manga. Existem diversas espécies de Mangífera com características potencialmente importantes no melhoramento genético da manga no Brasil, bastando apenas que sejam introduzidas, avaliadas e selecionadas. A Mangifera pajang, por exemplo, poderia ser usada como genitor em cruzamento para a obtenção de híbrido interespecífico que apresente a retirada da casca como se fosse banana; já a $M$. casturi e $M$. griffithii produziriam progênies cujos frutos negros seriam usados na decoração de salas e mesas de jantar. No entanto, o BAG da Embrapa Semiárido possui apenas 3 espécies: a M. foetida, M. odorata e M. similis, sendo que apenas as duas primeiras têm características interessantes e inovadoras (Tabela 1). Com relação ao mercado atual, a variedade norte-americana 'Tommy Atkins' ainda ostenta a liderança na produção e exportação da manga fresca (in natura) brasileira, apesar da baixa qualidade quanto ao sabor e coloração da polpa, e vários outros problemas no manejo de campo já citados anteriormente. Atualmente, outras variedades norte-americanas, como a 'Palmer' e a 'Kent', vêm ganhando a preferência do mercado brasileiro devido às características superiores do fruto para consumo a fresco, embora alguns problemas no manejo de campo como a suscetibilidade à malformação e mosca-das-frutas são similares à 'Tommy Atkins'. Diversas variedades têm sido desenvolvidas em programas de melhoramento genético de instituições de diferentes países visando a substituição gradativa da 'Tommy Atkins' e/ou a diversificação qualitativa de manga no mercado consumidor. Um exemplo disso é a variedade brasileira 'Alfa' (Figura 1), cujas características de qualidade do fruto (coloração rósea e polpa doce) juntam-se à sua grande resistência à antracnose e à mosca-das-frutas (PINTO, 2000; ROSSETTO et al., 2006).

Variedades que possuem características aceitáveis para o consumo a fresco, para uso em processados e, finalmente, com dupla finalidade, são encontradas em programas de melhoramento genético de diversos países. No entanto, existem ainda inúmeras e excelentes variedades de manga de outros países que não constam registradas nos BAGs e/ou Coleções brasileiras e que poderiam ser introduzidas para uso como parentais, visando ao melhoramento genético da manga no Brasil (Tabela 2).

A variedade 'Ubá' é tradicionalmente usada na produção de suco por indústria processadora de manga no Estado de Minas Gerais, devido ao seu alto teor de açúcares (Brix $>20 \%$ ). Não obstante, o rendimento de polpa dessa variedade é muito baixo $(<60 \%)$ e pouco aconselhável como variedade para a agroindústria quanto a essa característica. Talvez o uso dessa variedade seja quase obrigatório por ser a única conhecida e em grande disponibilidade na região, o que facilita a demanda pelos proprietários da indústria processadora. No entanto, existem variedades de manga nos diferentes BAGs ou Coleções de instituições nacionais e internacionais, como a 'Mallika' e a 'Alphonso' na India, ou variedades dispersas naturalmente em algumas regiões brasileiras ("Landraces"), como as mangas 'Mamão' e 'Coité', importantes para agroindústria no Nordeste. Essas variedades na India e aqui no Brasil produzem frutos com Brix superior a 17-18\% e rendimento de polpa acima de $80 \%$, características que, em conjunto, são excelentes para produção de suco e poderiam ser selecionadas como parentais no programa de melhoramento genético, visando à obtenção de progênies superiores à 'Ubá' quanto às características para produção de suco.

A escolha do método ou métodos mais eficiente, rápido e de baixo custo, na obtenção das progênies desejadas em seus objetivos é, sem dúvida, uma importante decisão do melhorista. Os métodos confundem-se com a própria estratégia e as ferramentas a serem usadas pelo melhorista e quase sempre são usados de forma conjunta, complementando-se 
uns aos outros, tendo em vista maior eficiência na busca da variedade de "manga ideal".

A seleção precoce de genótipos desejáveis pode tornar o método de Seleção Recorrente mais eficiente, uma vez que a biotecnologia pode ser uma importante ferramenta de auxílio a esse método. Existem várias estratégias que têm sido adotadas na seleção fenotípica individual, visando a aumentar sua eficiência. A primeira é o estabelecimento de pomares para a produção de progênies de polinização aberta para avaliação e seleção. A segunda é a eliminação, nesses pomares-matrizes, de variedades com características indesejáveis em termos de tamanho, coloração e sabor de frutos e a inclusão de novos genótipos, visando sempre a melhorar a qualidade média do pólen que irá originar as progênies meio-irmãs para avaliação e seleção. E, finalmente, a terceira é a seleção, a multiplicação vegetativa e a avaliação de progênies superiores a partir desses pomares-matrizes em diferentes condições ambientais. Esse processo de seleção pode originar, diretamente, novas variedades ou progênies superiores para o estabelecimento de novos pomares-fontes para produção de progênies superiores. Exemplos desses tipos de estratégias são encontrados em Israel, onde o pomar-matriz é constituído de 55 genótipos, sendo 35 cultivares e 20 seleções avançadas (TOMER et al., 1996), e na África do Sul, onde o pomar-fonte de progênies conta também com várias variedades selecionadas previamente ("plêiades") de onde 100 progênies de cada variedade são originadas anualmente (CILLIERS et al., 1996).

A hibridação intervarietal tem sido um importante método na obtenção de novas variedades de manga, apesar das dificuldades quanto ao número de combinações híbridas que podem ser avaliadas, ao limitado número de progênies híbridas obtidas e à baixa previsibilidade dos resultados dos cruzamentos devido à alta heterozigose dos genitores. Apesar dessas dificuldades, a Índia e o Brasil têm lançado excelentes variedades híbridas usando esse método, como 'Mallika' e 'Amrapali', a 'Alfa', 'Roxa', 'Lita', 'Beta' e 'Ômega' (SHARMA et al., 1972; PINTO, 1996). Para diminuir as dificuldades e tornar a metodologia da hibridação mais eficiente em busca de uma nova variedade, o policruzamento parece ser uma técnica muito interessante. A estratégia de uso de variedades mantidas em telados lado a lado ou uma planta com copa de enxertos de 2 diferentes variedades, cuja sincronia de florescimento facilitaria o policruzamento e a obtenção de híbridos intervarietais (CILLIERS et al., 1996; TOMER et al., 1996; PINTO, 1996; PINTO; FERREIRA, 1999). Porém, para aplicar essa estratégia, é importante utilizar porta-enxertos ananicantes, a fim de que facilitem o manejo das variedades-copa em cruzamento (PINTO; BYRNE, 1993).

Outra alternativa seria a formação do campo de policruzamento, de tal forma que a chance de um dado parental aparecer lado a lado com os demais parentais seja maximizada. Para se conseguir isso, o ideal é que o número de vezes em que um determinado parental aparece no campo seja igual ao número total de parentais (STUBER, 1980), pois, nesse caso, cada parental terá a oportunidade real de polinizar e de ser polinizado por todos os demais parentais. Por exemplo, se 25 parentais são selecionados para formar um campo de policruzamento, então o número total de plantas nesse campo será de 625 , e cada parental contribuirá com 25 plantas, todas originadas de propagação vegetativa. Normalmente, utilizam-se, para se fazer esse arranjo, os delineamentos experimentais de blocos ao acaso ou do quadrado latino (FEHR, 1987; BORÉM; CAVASSIM, 1999).

Se as variedades apresentarem períodos de florescimento diferentes, porém o local do campo de policruzamento for irrigado, a chance nos cruzamentos poderá ser garantido com o uso da técnica de indução floral. Essa técnica garantirá o florescimento de todas as plantas ou mesmo a sincronia de florescimento entre as mesmas, facilitando a polinização, fecundação e obtenção de novas progênies. Adicionalmente, o plantio adensado de progênies no campo e a estratégia do uso do marcador morfológico usando a cor da panícula ligado à cor do fruto, ou seja, panículas vermelhas dão frutos vermelhos, e panículas amarelas a verdes dão frutos amarelos ou verdes, seria muito importante. Portanto, a indução floral e o marcador morfológico da cor da panícula permitiriam a eliminação precoce ou "roguing" de progênies indesejáveis quanto à característica de cor dos frutos. 
TABELA 1 - Características importantes de diferentes espécies do gênero Mangifera com potencial para uso no melhoramento genético.

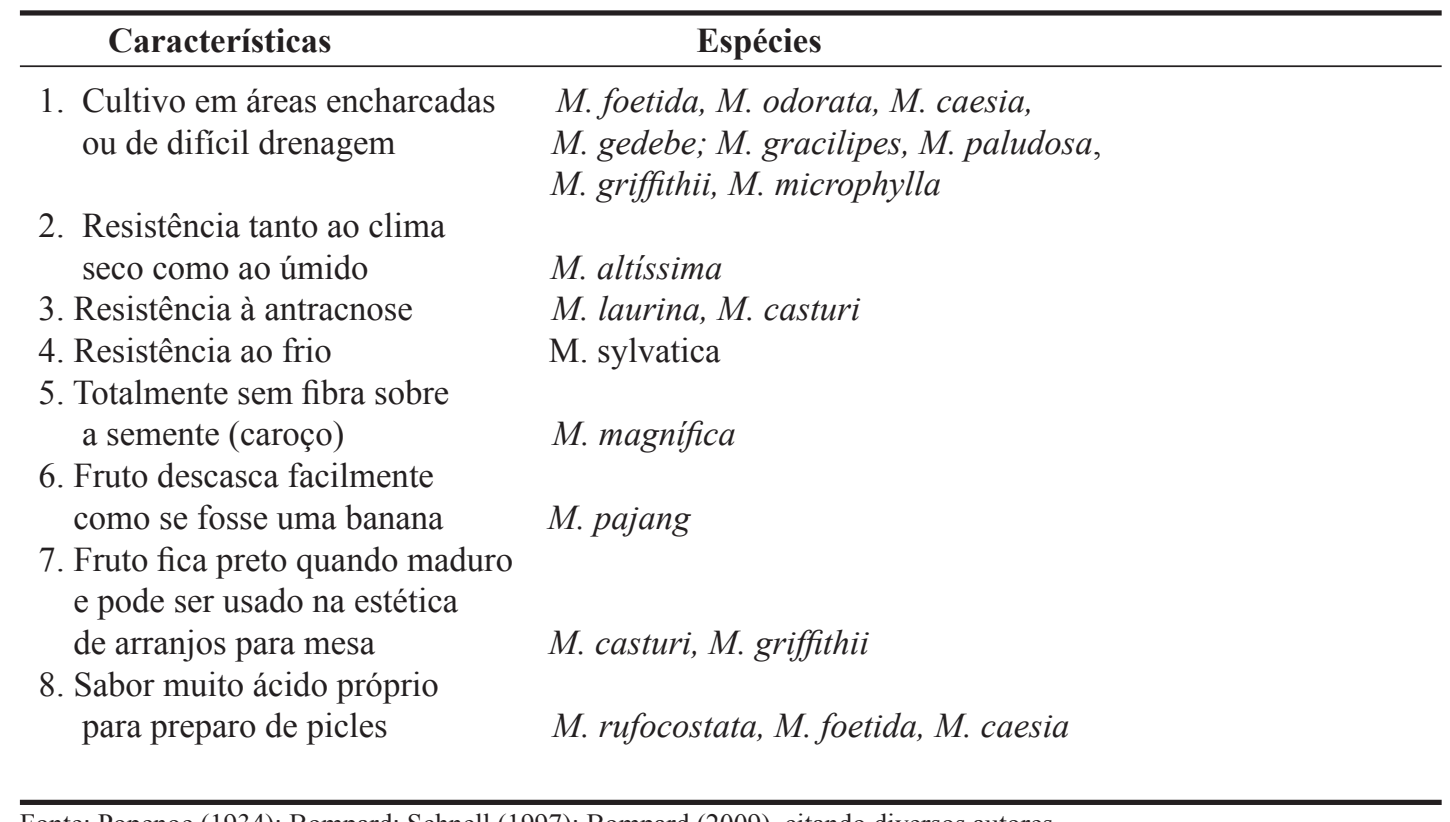

Fonte: Popenoe (1934); Bompard; Schnell (1997); Bompard (2009), citando diversos autores.

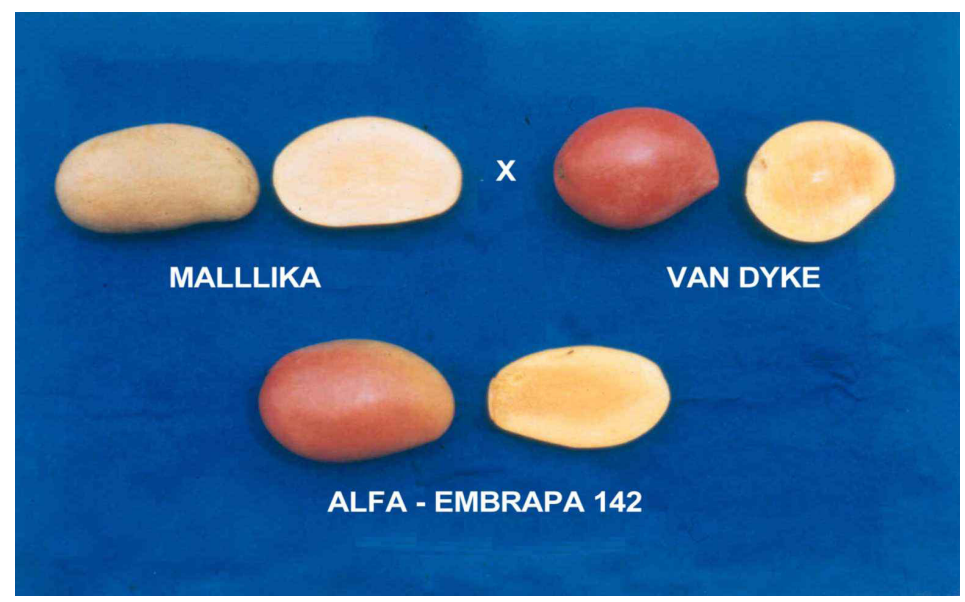

FIGURA 1 - Variedade Alfa possui fruto de coloração rósea, polpa doce e mediana em fibra, sendo muito resistente à mosca-das-frutas e à antracnose. 
TABELA 2 - Algumas variedades e seleções de manga com excelentes características para consumo in natura, processamento e/ou dupla finalidade com potencial para introdução e uso como parentais nos trabalhos de melhoramento genético no Brasil.

\begin{tabular}{|c|c|c|}
\hline Origem & Variedade ou & Comentário, Característica e Recomendação de Uso \\
\hline & Seleção & In Natura $\quad$ Processado $\quad$ Dupla Finalidade \\
\hline \multirow[b]{2}{*}{$\begin{array}{l}\text { África do } \\
\quad \text { Sul }\end{array}$} & A2B26 & $\begin{array}{l}\text { Pode ser consumida in natura e excelente indicação } \\
\text { para uso na produção de suco e polpa desidratada. }\end{array}$ \\
\hline & $\mathrm{C} 2 / \mathrm{D} 2-\mathrm{T} 13$ & 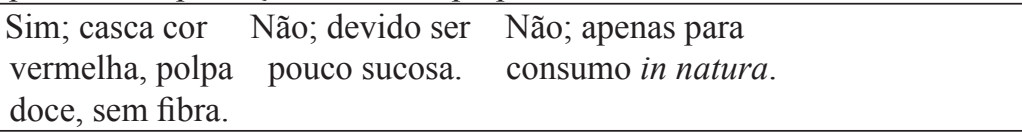 \\
\hline Austrália & $\begin{array}{l}\text { NMBP } 1201 \\
\text { NMBP } 1243 \\
\text { NMBP } 4069 \\
\end{array}$ & $\begin{array}{l}\text { São seleções ainda não licenciadas; possuem casca vermelha, polpa sem } \\
\text { fibra e doce, e podem ser recomendadas para dupla finalidade (ainda em } \\
\text { teste). }\end{array}$ \\
\hline \multirow[b]{2}{*}{ Egito } & 'Mabrouka' & $\begin{array}{l}\text { Casca de cor vermelha, polpa de bom rendimento, } \\
\text { bastante sucosa e doce, própria para dupla finalidade }\end{array}$ \\
\hline & 'Taimour' & $\begin{array}{lll}\begin{array}{l}\text { Não; cor casca } \\
\text { verde. }\end{array} & \begin{array}{l}\text { Sim; para suco } \\
\text { principalmente. }\end{array} & \begin{array}{c}\text { Não; para suco } \\
\text { somente. }\end{array} \\
\end{array}$ \\
\hline Haiti & 'Madame Francis' & $\begin{array}{l}\text { Apesar de casca amarela-esverdeada, fruto tem polpa } \\
\text { sucosa e doce, sendo indicado para dupla finalidade. }\end{array}$ \\
\hline \multirow[b]{2}{*}{ India } & $\begin{array}{l}\text { 'Fernandin' } \\
\text { 'Pairi' }\end{array}$ & $\begin{array}{l}\text { Casca vermelha com laivos amarelos, polpa doce e } \\
\text { sucosa, podem ser usadas com dupla finalidade. }\end{array}$ \\
\hline & $\begin{array}{l}\text { 'Ratna', 'Kesar' } \\
\text { 'Himsagar' e } \\
\text { 'Suvarnarekha' }\end{array}$ & $\begin{array}{l}\text { Apesar de casca amarela, frutos dessas variedades } \\
\text { são sucosos e doces; frutos cv Kesar se comem com } \\
\text { colher; todos são usados com dupla finalidade. }\end{array}$ \\
\hline Israel & $\begin{array}{l}\text { 'Naomi', 'Shelly' } \\
\text { 'Tango', 'Tahar' }\end{array}$ & $\begin{array}{l}\text { Todas com cor de casca vermelha, polpa muito doce; } \\
\text { desenvolvidas para consumo in natura apenas. }\end{array}$ \\
\hline Tailândia & $\begin{array}{l}\text { 'Kheo Savoy' } \\
\text { 'Nuwun Chan' }\end{array}$ & $\begin{array}{l}\text { Possuem frutos de casca amarela, com polpa sucosa } \\
\text { e muito doce, servem para uso de dupla finalidade. }\end{array}$ \\
\hline \multirow{2}{*}{$\begin{array}{c}\text { USA } \\
\text { (Flórida) }\end{array}$} & ‘Cogshall’ & $\begin{array}{ll}\text { Sim; Casca de } & \text { Não; apenas para consumo in } \\
\text { cor vermelha } & \text { natura devido ser pouco sucosa. }\end{array}$ \\
\hline & 'Osteen’ & $\begin{array}{l}\text { Cor casca amarelo-avermelhada, polpa firme, sucosa } \\
\text { e doce, podendo servir para dupla finalidade. }\end{array}$ \\
\hline
\end{tabular}

Fonte: Gunjate et al. (2004); Human et al.(2009); Knight Jr. et al. (2009); Pinto et al. (2002);

\section{CONCLUSÕES}

Os resultados e discussões apresentados nesse trabalho permitem algumas conclusões importantes que facilitarão decisões futuras, a saber:

1. A mudança na demanda por determinada variedade tem sido relativamente rápida, e sua dinâmica de mercado é muito influenciada por grupos étnicos ou pela pressão de empresas produtoras, processadoras e exportadoras de frutos de acordo com seus interesses.

2. A introdução, avaliação e seleção de espécies que mostram características inovadoras interessantes no mercado, bem como de variedades com características de dupla finalidade comercial (consumo in natura e para produção de processados) que poderão fortalecer a opção na oferta de grupos parentais que propiciem a obtenção de novas e excelentes variedades.

3. O uso combinado de novas estratégias como a metodologia de seleção fenotípica individual com auxílio da biotecnologia, a hibridação intervarietal com o policruzamento com duas variedades enxertadas sobre uma mesma copa é uma excelente decisão. Outra alternativa seria a instalação de campos de policruzamentos irrigados e adensados com sincronia do florescimento feita com o auxílio da indução floral os quais favorecerão a seleção e o descarte de progênies indesejáveis ("roguing"), tornando o método mais eficiente. 


\section{AGRADECIMENTOS}

Os autores agradecem ao Dr. Eli Tomer (Volcani Center, Israel), Dr. Richard Campbell (Fairchild Garden, Florida) e Dr. Ian Balli (Austrália), pelas informações sobre as variedades importantes de seus países.

\section{REFERÊNCIAS}

BOMPARD, J.M. Taxonomy and systematics. In: LITZ, R. (Ed.). The Mango, botany, production and uses. $2^{\text {nd }}$ ed. Wallingford: CAB, 2009. p.19-41.

BOMPARD, J.M.; SCHNELL, R. Taxonomy and systematic. In: LITZ, R. (Ed.). The Mango, botany, production and uses. Wallingford: CAB, 1997. p. 21-48.

BORÉM, A.; CAVASSIM, J.E. Blocos de Cruzamentos. In: BORÉM, A. (Ed). Hibridação artificial em plantas. Viçosa: UFV, 1999. p. 15-61.

BRETTELL, R.I.S.; JOHNSON, P.R.; KULKARNI, V.J.; MULLER, W.; BALLY, I.S.E. Inheritance of fruit characters in hybrid mangoes produced through controlled pollination. Acta Horticulturae, The Hague, n.645, p.319-326, 2004.

CILLIERS, B.; HUMAN, C.F.; SNYMAN, J.C.; CARSTENS, K. Strategies, Progress and Results from the South African Mango Breeding Programme. Acta Horticulturae, The Hague, v.455, p.241-244, 1996.

FEHR, W.R. Principles of cultivar improvement: theory and technique. New York: Macmillan Publishing Company, 1987. v.1, 536 p.

GRANÇO, G.; MORAES, M.A.F.D. Padrões Técnicos e Custo de Transação na Exploração da Manga para a União Européia. In: CONGRESSO DA SOBER, 48., 2010, Campo Grande. Anais... p.116. Disponível em: <www.sober.org.br/palestras>. Acesso em: 10 maio 2011.

GUNJATE, R.T.; KUMBHAR, A.R.; THIMAIAH, I.M.; AMIN, S.M. Performance of some Indian and exotic mango cultivars under high density planting in arid conditions of Gujarat (India). Acta Horticulturae, The Hague, n. 645, p. 347-351, 2004.
HUMAN, C.F.; RHEEDER, S; SIPPEL, A.D. New cultivars and hybrid selections from the Mango Breeding Program of the Agricultural Research Council in South Africa. Acta Horticulturae, The Hague, n. 820, p. 119-126, 2009.

IBRAF. Disponível em: $<$ http://www.rionegronews. net>. Acesso em: 25 fev. 2011.

IYER, C.P.A.; DEGANI, C. Classical Breeding and Genetics. In: LITZ, R.E. (Ed.). The Mango, botany, production and uses. New York: CAB International, 1997. p. 49-68.

IYER, C.P.A.; DINESH, M.R. Advances in classical breeding and genetics in mango. Acta Horticulturae, The Hague, v.455, p. 252-267, 1996.

KNIGHT, Jr., R.J.; CAMPBELL, R.J.; MAGUIRE, I. Important mango cultivars and their descriptors. In: LITZ, R. (Ed.). The Mango, botany, production and uses. $2^{\text {nd }} e d$. Wallingford: $C A B, 2009$. p. 42-66.

LAVI, U.; KAUFMAN, D.; SHARON, D.; ADATO, A.; TOMER, E.; GAZIT, S.; HILLEL, J. Mango Breedng and Genetics - Review. Acta Horticulturae, The Hague, v. 455, p. 268-276, 1996.

LIMA, J.P.R.; MIRANDA, E.A. de A. Fruticultura irrigada no Vale do São Francisco: incorporação tecnológica, competitividade e sustentabilidade. In: ENCONTRO REGIONAL DE ESTUDOS DE TRABALHO - ABET, 3., 2000, Recife. Anais... Disponível em: <http://www.race.nuca.ie.ufrj.br/ abet/>. Acesso em: 20 maio 2011.

MAPA. Uma década de bons frutos. Informativo CGPCP Fruticultura, Brasília, v.5, n.46, p.1-7, 2011.

MENTEN, M.M. Clima favorece a mangicultura em 2010. Hortifruit Brasil, São Paulo, p. 42-43, 2010.

PINTO, A.C. de Q; BYRNE, D.H. Mango hybridization studies in tropical Savannah ("Cerrados") of Brazil. Acta Horticulture, The Hague, v.341, p.98-06, 1993. 
PINTO, A.C. de Q. Melhoramento da mangueira (Mangifera indica L.) no ecossistema dos Cerrados do Brasil Central por meio da hibridação. Pesquisa Agropecuária Brasileira, Brasília, v.30, n.3, p.369374, 1996.

PINTO, A.C. de Q. Manga 'Alfa'. In: DONADIO, L.C. (Ed.). Novas variedades brasileiras de frutas. Jaboticabal: Sociedade brasileira de Fruticultura, 2000. p. 136-137.

PINTO, A.C. de Q.; COSTA, J.G.; SANTOS, C.A.F. Principais Variedades. In: GENÚ, P.J.C.; PINTO, A.C.Q. (Ed.). A cultura da mangueira. Brasília: Embrapa Informação Tecnológica, 2002. p. 94-116.

PINTO, A.C. de Q.; FERREIRA, F.R. Recursos genéticos e melhoramento da mangueira no brasil. In: QUEIRÓZ, M.A. DE; GOEDERT, C.O.; RAMOS, S.R.R. (Eds.). Recursos genéticos e melhoramento de plantas para o nordeste brasileiro. Petrolina: Embrapa Semi-Árido, 1999. Disponível em: <http:// www.cpatsa.embrapa.br>. Acesso em: 25 jan. 2011.

POPENOE, W. Manual of tropical and subtropical fruits: the mango. New York: MacMillan Company, 1934. p. 79-175.

ROSSETTO, C.J.; RIBEIRO, I.J.A., GALLO, P.B.; BORTOLETTO, N.; PAULO, E.M. Mango breeding for resistance to diseases and pests. Acta Horticulturae, The Hague, v. 455, p. 299-304, 1996.
ROSSETTO, C.J.; BORTOLETTO, N.; WALDER, J.M.M.; MASTRÂNGELO, T. de A.; CARVALHO, C.R.L.; CASTRO, J.V.de; PINTO, A.C. de Q.; CORTELAZZO, A.L. Mango resistance to fruit flies. II Resistance of the Alfa cultivar. In: INTERNATIONAL SYMPOSIUM ON FRUIT FLIES OF ECONOMIC IMPORTANCE, 7., 2006, Salvador. Proceedings... p.1-19.

SAÚCO, V.G. Mango: emerging tropical exporting crop. Chronica Horticulturae, Wageningen, v. 42, n. 4, p. 14-17, 2002.

SAÚCO, V.G. EI cultivo del mango. Madrid: Mundi Prensa, 1999. 297 p.

STUBER, C.W. Mating designs, field nursery lay-outs and breeding records. In: FEHR, W.R.; HARDLEY, H.H. (Ed.). Hybridization of crop plants. Madison: American Society of Agronomy, 1980. p. 83-104,

TOMER, E.; GAZIT, S.; LAVI, U.; SHOKER, S.; RIPA, M; ZIPORI, I.; SA'ADA, D. Mango breeding in israel - principals and difficulties. Acta Horticulturae, The Hague, v. 455, p. 245-251, 1996. 